\title{
ECOS DE PASSIONALIDADE E A HERANÇA MATERNA: UMA BREVE ANÁLISE DA CONSTRUÇÃO DE IMAGENS DO FEMININO EM
}

\section{LAVOURARCAICA ${ }^{1}$}

Allana Mátar de Figueiredo - FALE/UFMG

\section{1. (RE)DIRECIONANDO OS OLHARES: FEMININO, CINEMA BRASILEIRO E DISCURSO}

Nas últimas décadas, tem-se assistido, nos mais diversos campos científicos, a um crescimento notório dos estudos que tangem a temática do feminino. Segundo Michelle Perrot (2007, p. 19), historiadora francesa, tal fenômeno se deve ao fato de que o real advento da "história das mulheres" - ou a emergência de atenções para o objeto mulher - somente se deu a partir da década de 1960, na Grã-Bretanha e nos Estados Unidos, e na França, uma década depois, por motivos diversos, o que possibilitou quebrar, pouco a pouco, um longo jejum de silenciamento feminino nos mais diversos relatos sociais, em todo o mundo.

Exemplo de como o feminino passou a ganhar notoriedade nas ciências pós-década de 1950 são os próprios estudos da Análise do Discurso. Tendo sua gênese no fim da década de 1960 e no começo da década de 1970, inicialmente com os trabalhos de Pêcheux -, a AD, tais como outras áreas afins, a exemplo da Sociologia, da História e da Psicologia, tem colaborado para a expansão desse interesse pela figura feminina, dando-lhe voz das mais diversas formas, especialmente na contemporaneidade. Também pode ser destacada, nessa interface estudos da linguagem/feminino, a própria ascensão e disseminação dos Estudos Culturais.

\footnotetext{
${ }^{1}$ Cabe ressaltar que o presente trabalho é apenas parte de um artigo mais extenso, produzido em caráter de Iniciação Científica pela autora durante o ano de 2009. Esse artigo foi resultado das atividades do Grupo de Pesquisas Representações do Feminino no Cinema Brasileiro, coordenado e orientado pela Profa. Dra. Helcira Lima (FALE/UFMG).
} 
Nas últimas décadas, observa-se que a sensível abordagem dos papéis da mulher tem alcançado também, como era de se esperar, a ambiência artística, como o teatro, as artes plásticas e o cinema. No contexto nacional, assistiu-se especialmente, nos últimos anos, ao crescimento da sétima arte e da produção de inúmeros longas-metragens de relevância. A essa recente fase, dá-se o nome de “Cinema de Retomada Brasileiro", época de produção de inúmeros filmes que nos possibilitaram, dentre outras temáticas, interessantes e múltiplas abordagens da figura feminina.

É nesse contexto de valorização do feminino em diversos campos científicos - especialmente nas ciências humanas - e artísticos, de forma ampla, que se enquadra o presente artigo. Tomou-se como ponto de partida o longa-metragem LavourArcaica (2001), de Luiz Fernando Carvalho, objetivando-se estudar algumas representações femininas neste filme nacional. No presente trabalho, focaliza-se, em especial, a figura da mãe, em sua relação sui generis com o protagonista André e em sua inserção no seio familiar. A partir de perspectivas da Análise do Discurso centradas na revisão da tríade retórica ethos, pathos e logos - por meio de autores como Patrick Charaudeau, Ruth Amossy e Helcira Lima -, e em teorias sociológicas interessadas na questão feminina - como certos trabalhos de Pierre Bourdieu e de Michelle Perrot ${ }^{2}$-, efetuar-se-á, especialmente, uma breve abordagem de algumas imagens construídas no discurso de André, para si e para sua mãe, assim como de certos recursos utilizados por ele para suscitar emoções que o auxiliem nessa construção. Além disso, buscaremos verificar alguns imaginários sociodiscursivos que estão envolvidos na representação dessa matriarca e do feminino, a partir do discurso de André e dos discursos que circulam em nossa sociedade sobre as mulheres, de um modo geral. Por fim, procuraremos confirmar a hipótese de que haveria - a partir das possíveis correspondências na construção de mãe e filho certa aproximação de André a representações do âmbito do feminino no filme em questão.

Certamente, não temos a ilusão de encontrar "certezas" na análise proposta, assim como não temos a pretensão irreal de esgotá-la neste único artigo.

\footnotetext{
${ }^{2}$ Por questões de extensão, o presente trabalho não poderá se deter minuciosamente nos referenciais teóricos elegidos no estudo original.
} 
Tal impossibilidade dá-se não só por motivos de extensão, como também por julgarmos que o objeto fílmico escolhido não é dos mais simples. LavourArcaica, como veremos a seguir, marca-se, em suas quase três horas de duração, como um dos filmes mais herméticos e densos do cinema brasileiro. Além disso, é importante destacar-se que não desprezamos os variados e importantes estudos literáriopsicanalíticos já efetuados acerca desse longa-metragem, o que poderia ser questionado pelo fato de praticamente não utilizarmos pressupostos teóricos dessas áreas do saber no presente artigo. Pelo contrário: temos consciência de que muitas questões presentes no filme são valiosamente elucidadas somente pela Psicanálise e pela Teoria Literária. Todavia, nestas páginas, apenas almejamos, arriscadamente, esboçar algumas linhas sobre o filme em questão a partir de um viés, de certa maneira, diferenciado e inédito - que é o da Análise do Discurso -, mas não menos rico, por contemplar diversas questões sociohistóricas, culturais e discursivas.

\section{LAVOURARCAICA: “A EXPERIÊNCIA ESTÉTICA ‘COMPLETA””}

LavourArcaica $^{3}$ (Europa Filmes, 2001), filme escolhido como objeto desta pesquisa, tem direção, montagem, edição de som e roteiro de Luiz Fernando Carvalho, que transcriou o texto literário original de Raduan Nassar, Lavoura Arcaica (1975), para a ambiência cinematográfica. Este filme é o primeiro longa-metragem do diretor, que faz participações na Rede Globo de Televisão, na maioria das vezes inspiradas em releituras de obras literárias.

A vinculação de LavourArcaica à Rede Globo de Televisão não se restringe aos laços profissionais de Carvalho. A própria distribuidora do longa, a Europa Filmes, é afiliada da Globo Filmes. Nasce daí o paradoxo em que se insere Lavoura: apesar de alguma maneira vinculado ao padrão "Globo de qualidade", o longa, sem dúvida, vai na contramão estética da maioria dos filmes da Retomada

\footnotetext{
${ }^{3}$ Optamos por, neste trabalho, referirmo-nos ao longa-metragem como LavourArcaica, com a elipse que marca a grafia do DVD em sua embalagem e créditos, a fim de o diferenciarmos da obra literária de Nassar, grafada como Lavoura Arcaica, sem a fusão entre os nomes.
} 
filiados a esse padrão, fato que pode ser considerado, em seu caso, um ponto positivo. Butcher (2005, p. 84), nesse sentido, aponta-nos que LavourArcaica se enquadra na lista de filmes de ficção realizados contra a corrente da hegemonia audiovisual brasileira e é, para muitos críticos, "o filme mais importante da Retomada, em sua leitura ao mesmo tempo fiel e particular do livro homônimo de Raduan Nassar”. LavourArcaica não se destaca apenas por sua qualidade técnica - o que o levou a ser um dos filmes brasileiros mais premiados, nacional e internacionalmente -, como também por sua apreciável dicção poética e imagética, rara no contexto realista e objetivo da Retomada, marcado por filmes produzidos a fim de atingir o público de massa. Além dele, o crítico de cinema Daniel Piza, em resenha publicada no jornal Estado de São Paulo em novembro de $2001^{4}$, também destaca o fato de LavourArcaica não se homogeneizar em meio à maioria das produções nacionais recentes, graças a sua complexidade:

O filme tem, enfim, a saudável ambição - até agora invisível na retomada do cinema brasileiro - da experiência estética "completa", com as imagens, as falas e os sons em mútua potenciação.

É essa singularidade de LavourArcaica que nos fez elegê-lo como objeto de estudo, porquanto entendamos que é tal complexidade (e hermeticidade) do longa que faz com que as representações femininas construídas nele tornem-se mais instigantes e multifacetadas. Além disso, o filme de Carvalho também nos proporciona uma interessante abordagem do feminino por colocar a figura da mulher em destaque sem necessariamente dar-lhe voz e notoriedade aparentes - 0 que será claramente perceptível, por exemplo, no significativo silenciamento da personagem da matriarca do longa. Nas poucas falas das personagens femininas, há muito a ser dito: "O silêncio é uma outra forma de expressão. O silêncio fala" (MELLO, 2008, p. 2590).

Por fim, faz-se relevante efetuarmos um breve percurso pela diegese de LavourArcaica. Este filme retrata a trágica história de André (Selton Mello), o filho 'desgarrado' de uma tradicional família rural de origem libanesa, que foge de casa por sentir-se sufocado pela lei de ordem e rigidez do pai Yohana (Raul Cortez). Lei

\footnotetext{
${ }^{4}$ Texto presente no encarte anexo a LAVOURA ARCAICA. Dir. Luiz Fernando Carvalho. Drama. Brasil: Europa Filmes, 2001. 163 min., cor, DVD duplo de extras.
} 
esta oposta a todo o afeto recebido de sua mãe (Juliana Carneiro da Cunha) e à paixão incestuosa por sua irmã Ana (Simone Spoladore). Pedro (Leonardo Medeiros), o irmão mais velho, recebe, então, da mãe, a tarefa de trazer o irmão de volta ao lar, após visitá-lo em um solitário quarto de pensão interiorana. No momento em que os irmãos se reencontram, tem-se conhecimento das lembranças de André e dos densos motivos de sua fuga, além de seus intensos impulsos e vivências, guiados pelo desejo, fora das terras do clã. Cedendo aos apelos da mãe e do irmão, André retorna à sua casa, falido em seus projetos de ruptura e afirmação. Segundo o diretor Luiz Fernando Carvalho, na sinopse do filme escrita por ele, Lavoura Arcaica é a "versão ao avesso da parábola do Filho Pródigo"”.

\section{A TRÍADE ETHOS, PATHOS E LOGOS: DA ORIGEM CLÁSSICA DOS ESTUDOS SOBRE A ARGUMENTAÇÃO À ANÁLISE DO DISCURSO CONTEMPORÂNEA}

O presente trabalho, como já mencionado, firmará suas bases de análise sobre a releitura, pela Análise do Discurso, da tríade aristotélica ethos, pathos e logos, focando, especialmente, os dois primeiros componentes desta. Antes de chegarmos a algumas visões contemporâneas da AD sobre a revalorização de tais provas do discurso e, consequentemente, da argumentação, é preciso retornarmos brevemente à origem de tal tríade: à Retórica Clássica.

Segundo Charaudeau \& Maingueneau (2008, p. 52), "a argumentação está no centro da concepção antiga da Retórica". Foram os preceitos desenvolvidos e sistematizados por Aristóteles, a respeito da utilidade da disciplina Retórica, que serviram de base para o desenvolvimento de todas as teorias da argumentação que surgiram depois dele, segundo Lima (2006, p. 91). Dentre esses preceitos, há que se destacar, especialmente, as três provas inerentes ao discurso: ethos, pathos e logos. Enquanto o logos representaria, grosso modo, a argumentação em si (eixo, de certa maneira, mais "racional”, sobre o qual Aristóteles privilegiou suas abordagens sobre

\footnotetext{
${ }^{5}$ Texto presente no encarte anexo a LAVOURA ARCAICA. Dir. Luiz Fernando Carvalho. Drama. Brasil: Europa Filmes, 2001. 163 min., cor, DVD duplo de extras.
} 
a persuasão), o pathos se vincularia à relação com os ouvintes e o ethos estaria ligado a uma postura a ser seguida pelo orador para tornar seu discurso eficaz frente a esses ouvintes. Posteriormente, também os romanos, especialmente Cícero, retomam a tríade aristotélica, proporcionando novas leituras sobre ela.

Acabado o período clássico, em que a Retórica assistiu a seu apogeu, tem-se um outro momento dessa disciplina. Segundo Lima (2006, p. 96), após um período de ostracismo na Idade Média, durante o qual a Igreja tomou para si tudo que era referente à Retórica para impedir o fortalecimento do discurso de seus opositores, foram efetivamente as ideias renascentistas e cientificistas dos séculos posteriores que contribuíram fortemente para o descrédito dessa disciplina. Passando a ser vista, então, somente como sinônimo de engodo ou como técnica de embelezamento do texto - por meio de uma lista de figuras de expressão do discurso -, a Retórica caiu no esquecimento e até mesmo sofreu preconceito. A disciplina foi esvaziada, uma vez que seu objetivo inicial, a argumentação, foi colocado de lado.

Depois do longo período de desconfiança em relação aos estudos retóricos, apenas a partir dos anos 1960 o interesse pela argumentação ressurgiu, marcado pela obra Tratado da argumentação - A Nova Retórica, de Perelman e Olbrechts-Tyteca (lançada em 1958, mas estudada somente a partir da década de 1980) e pela Teoria da Argumentação na Língua (1989), de Ducrot. Todavia, foi mesmo nos anos 1990 que os estudos da argumentação retomaram sua efetiva força, seja graças à (re)descoberta da safra dos trabalhos de 1960 a 1980, seja graças às novas ideias de pesquisadores da área de Linguagens, especialmente da Análise do Discurso de linha francesa em sua segunda geração - destacando-se, por exemplo, Plantin, Ruth Amossy e Charaudeau. Tais analistas do discurso, aliados a contribuições da Pragmática, da Linguística Textual e de outras áreas afins, tiveram seus méritos na retomada dos estudos retóricos especialmente por revalorizarem as influências decisivas da construção de imagens (de si mesmo e também do outro, 
em acréscimo à teoria aristotélica) e das emoções ${ }^{6}$, até então postas em segundo plano, no jogo da argumentação.

Em meio a inúmeros estudos contemporâneos da Análise do Discurso sobre a construção de imagens de si e do outro na argumentação, destacamos a seguinte fala de Charaudeau (apud LIMA, 2006, p. 146), para quem o ethos estaria "relacionado ao cruzamento de olhares: olhar do outro sobre aquele que fala, olhar daquele que fala sobre a maneira que ele pensa que o outro o vê". Para ele, portanto, tal prova retórica referiria-se tanto ao locutor quanto ao enunciador, compondo-se de uma instância pré-discursiva e de outra propriamente discursiva. Dessa maneira, “o sentido que veiculam nossas falas depende ao mesmo tempo do que somos e do que dizemos. O ethos resulta dessa dupla identidade, a qual acaba por se fundir em apenas uma" (CHARAUDEAU apud LIMA, 2006, p. 147). Assim, "Todo ato de tomar a palavra implica a construção de uma imagem de si" (AMOSSY, 2005, p. 9), já que o orador tentaria incessantemente, em seu discurso, mesmo sem perceber, delinear uma representação de si mesmo frente ao outro, este por vezes também construído/projetado em sua fala.

Já em relação à dimensão patêmica da argumentação, sabe-se que, desde os gregos, o pathos, sendo considerado a prova do discurso relacionada às disposições persuasivas dos ouvintes e à inspiração de suas paixões para o convencimento, é entendido como parte fundamental do processo de argumentação. Segundo Charaudeau (MACHADO et all., 2007, p. 242), na obra de Aristóteles, "persuadir um auditório consiste em produzir nele sentimentos que o predispõem a partilhar o ponto de vista do orador". Para Lima (2006), em uma proposta contemporânea da Análise do Discurso, a instância patêmica da argumentação diz respeito à mobilização das emoções dos sujeitos com fins persuasivos. Essas emoções seriam, nesse sentido, movidas por uma visée, por um objetivo - o que as vincularia a uma perspectiva, de certa maneira, racional - e não somente à instabilidade dos afetos, como apregoa o senso comum.

\footnotetext{
${ }^{6}$ Por vezes, neste trabalho, utilizaremos a nomenclatura "construção de imagens" e "emoções" no discurso no lugar de ethos e pathos, filiando-nos à proposta de Lima (2006) e a uma leitura contemporânea e mais elaborada da tríade retórica pela AD.
} 


\title{
4. REPRESENTAÇÕES DE PASSIONALIDADE: À IMAGEM DO FILHO, A MÃE
}

\begin{abstract}
Que culpa temos nós dessa planta da infância, de sua sedução, seu viço e constância? Que culpa temos nós se fomos duramente atingidos pelo vírus fatal dos afagos desmedidos?

(Raduan Nassar, Lavoura Arcaica)
\end{abstract}

A epígrafe anterior, trecho de uma fala de André no livro Lavoura Arcaica, fornece-nos um interessante ponto de partida para efetivarmos algumas linhas de análise sobre o filme homônimo. Será justamente a partir da relação de "afagos desmedidos" estabelecida entre o protagonista e sua mãe que verificaremos algumas imagens ${ }^{7}$ construídas por André para ela e para si mesmo em seu discurso, assim com as possíveis emoções a serem suscitadas pela fala do "filho pródigo".

Seja por diálogos ou pela narração em off que perpassa a película, é a voz de André que regerá a construção da diegese frente aos olhos do espectador, assim como boa parte das percepções e emoções deste. Sendo assim, o público tem acesso, na maior parte do filme, quase que somente ${ }^{8}$ à (precária) "verdade" de André, pois o que predomina é sua versão dos fatos, a sua necessidade de se justificar/revelar como o "filho pródigo" e incompreendido, as imagens construídas por ele e suas percepções afetivas dos acontecimentos. Tal condição é essencial para entendermos o discurso claramente argumentativo de André, em sua difícil defesa de si mesmo e de seus ideiais de ruptura e insatisfação, o que contaminará sobremaneira as representações femininas - nas quais, de alguma maneira, procuraremos mostrar que ele se enquadra - construídas pelo protagonista durante o longa-metragem. Seguindo preceitos básicos da Análise do Discurso, não acreditamos, entretanto, que o sujeito André é completamente "dono" de suas construções e representações; pelo contrário, como veremos a seguir, ele reverbera

\footnotetext{
${ }^{7}$ Mais uma vez, julga-se necessário ressaltar que o presente trabalho não poderá adentrar-se em muitas imagens e questões teóricas analisadas pela autora, devido a questões de extensão.

${ }^{8}$ É claro que não se desconsidera, nesta análise, o peso do discurso da tradição e da ordem, oposto ao de André e representado principalmente pelo irmão mais velho Pedro e pelo pai, Yohana. Todavia, pretendemos mostrar que, quantitativa e qualitativamente, é a voz de André, por meio de seu discurso extremamente patêmico, que predominará aos olhos do espectador.
} 
em sua fala inúmeros imaginários sociodiscursivos ${ }^{9}$ acerca da mulher e do feminino presentes em nossa sociedade (muitas vezes ligados a estereótipos), uma vez que, mesmo inserido em referências espaço-temporais pouco precisas ${ }^{10}$, o personagem, como qualquer indivíduo, espelha a cultura e o pensamento social e familiar em que está inserido. Assim, nos filiamos às ideias de Charaudeau (2006), segundo as quais a construção do discurso e dos ethé não se dá de forma totalmente "consciente" ou voluntária, já que o indivíduo transparece, em sua fala, os imaginários sociodiscursivos de que compartilha e possui, portanto, uma discurso simultaneamente livre e assujeitado.

Sigamos, portanto, para a análise de algumas cenas do filme, a fim de abordarmos o primeiro grande grupo de imagens construídas por André, baseadas em representações sociais relativas ao feminino bastante caras ao senso comum. Logo no início do longa, após vermos André receber a visita de seu irmão Pedro no quarto de pensão em que aquele se refugiava, temos acesso, simultaneamente, a uma série de flashes de momentos da infância e juventude do protagonista nas terras da família. Uma das primeiras recordações que o narrador-André nos apresenta é a seguinte, a respeito da configuração da mesa das refeições do clã:

Eram esses nossos lugares à mesa na hora das refeições ou na hora dos sermões: o pai à cabeceira; à sua direita, por ordem de idade, vinha primeiro Pedro, seguido de Rosa, Zuleika e Huda. À sua esquerda, vinha a mãe. Em seguida eu, Ana e Lula, o caçula. O galho da direita era um desenvolvimento espontâneo do tronco desde as suas raízes. Já o da esquerda trazia o estigma de uma cicatriz, como se a mãe, por onde começava o segundo galho, fosse uma anomalia, uma protuberância mórbida, pela carga de afeto.

Esta cena dá-se em meio à penumbra, em uma grande sala clareada somente por um candeeiro tremulante que se situa em frente ao pai, iluminando-o como a alguém digno de nota e respeito. Tal descrição feita por André será de

\footnotetext{
${ }^{9}$ Charaudeau (apud LIMA, 2006, p. 141) propõe que os imaginários sóciodiscursivos se referem ao conjunto de representações discursivas de um sujeito inscrito em uma coletividade, as quais se ligam às crenças e ao conhecimento e, consequentemente, à capacidade de ele avaliar o mundo ao seu redor.

${ }^{10}$ Segundo Sedlmayer (1997, p. 74), a ausência de referências explícitas de tempo e lugar nos quais se desenrolaria a diegese (consegue-se inferir, somente, que o clã é uma família de origem libanesa radicada em alguma zona rural brasileira, em meados do século $\mathrm{XX}$ ) acabaria por dar lugar, em LavourArcaica, à supervalorização dos afetos dos personagens, como poderá ser percebido em nossa análise.
} 
fundamental importância para entendermos a ligação entre ele e sua mãe: desde pequeno, André situava-se no "galho esquerdo" da mesa, ao lado esquerdo do pai. Essa posição de gauche, iniciada pela mãe e passada ao filho, assumirá, durante todo o filme, de acordo com as palavras de verdade do pai - das quais André discordava veementemente -, um caráter negativo e prejudicial. O lado esquerdo, que trazia o estigma de uma "cicatriz", de uma "anomalia", de uma "protuberância mórbida”, assim o era graças à “carga de afeto”, à passionalidade que o distinguia. A matriarca daquela família - ao contrário do pai Yohana, que era a representação clara e rígida da ordem e da austeridade, traços culturalmente atribuídos ao masculino - era marcada pelo transbordamento de afeto, pela emoção, traços tão desvalorizados pelos ideais do clã. E mais: ela, como o começo daquele galho esquerdo, tinha maculado também todo o restante dos integrantes simbolicamente pertencentes a ele: o protagonista André, transbordante de passionalidade como a mãe, assim como a irmã Ana e o caçula Lula, todos marcados pela "nódoa" do afeto. O lado esquerdo, como se verá no filme, será o distinto pela transgressão, de uma forma ou outra, à ordem do pai; segundo Sabrina Sedlmayer (1997, p. 46), é este lado que marca a procura por uma père version, "uma outra versão da palavra paterna”. O galho esquerdo, suscetível às paixões, ao desequilíbrio e à ruptura oriundos da mãe, representaria as "trevas", a perdição, enquanto o direito, em seu controle e racionalidade, seria a "luz" ", segundo o próprio discurso do patriarca Yohana: “O mundo das paixões é o mundo dos desequilíbrios: é preciso impedir que as trevas de um lado invadam e contaminem a luz do outro. (...) A paciência é a virtude das virtudes: não é sábio quem se desespera, nem sensato quem não se submete."

Essa cena da mesa de refeições nos leva a certos imaginários sociais e discursivos bastante comuns acerca do feminino. Segundo Pierre Bourdieu, em sua

\footnotetext{
${ }^{11}$ Esta oposição metafórica trevas/ luz é possível de ser percebida em várias traços do longa, até mesmo em sua fotografia. Momentos em que André está imerso na penumbra ou cenas de tons amarronzados parecem refletir o conflito interno do personagem, marcado pela passionalidade e pelo desejo (veja-se, por exemplo, a própria escuridão do quarto de pensão). Já momentos de claridade, como muitas das cenas da fazenda ou da infância do protagonista, refletem a submissão dos personagens à ordem paterna, à "clareza das ideias" e dos sentimentos que o pai pretendia instaurar. O próprio irmão Pedro, quando chega ao quarto escuro de pensão em que estava André, questiona-o, marcando sua filiação ao discurso da pai, ao discurso da "luz": "Por que as venezianas estão fechadas?", pouco antes de abri-las e deixar o quarto ser invadido pela claridade.
} 
obra A Dominação Masculina (1999), haveria se constituído durante os séculos, nas mais diversas sociedades, uma naturalização das oposições entre homem e mulher, como se uma divisão arbitrária e sexualizante do mundo regesse o que deveria ser próprio do masculino, do dominante, e, do lado rigidamente contrário, o que deveria ser caro ao feminino, ao dominado:

\begin{abstract}
Arbitrária em estado isolado, a divisão das coisas e das atividades (sexuais e outras) segundo a oposição entre o masculino e o feminino recebe sua necessidade objetiva e subjetiva de sua inserção em um sistema de oposições homólogas, alto/baixo, em cima/embaixo, na frente/atrás, direita/esquerda, reto/curvo (e falso), seco/úmido, duro/mole, temperado/insosso, claro/escuro, fora (público)/dentro (privado) etc. [...]. (BOURDIEU, 1999, p. 16, grifo nosso).
\end{abstract}

Dessa maneira, segundo o sociólogo, esses “esquemas de pensamento", de aplicação universal, registrariam como que diferenças da natureza que estariam inscritas na "ordem das coisas", sendo naturalizadas socialmente na doxa. A Família, inclusive (instituição social em foco em LavourArcaica), teria papel fundamental na naturalização desses esquemas, criando como diferentes, desde cedo, meninos e meninas, e ensinando-lhes uma lógica de mundo oposta, na qual as mulheres acabariam, de forma ou outra, relegadas a um papel inferior e submisso frente ao homem - apesar de essas acabarem por enquadrar-se na mentalidade de naturalização dos dominadores e não se aperceberem dominadas.

Sob esse ponto de vista, conforme Bourdieu, às mulheres seria reservado o esquerdo (aí visto em sua porção pejorativa, gauche, transviada, ruptora, desequilibrada) e aos homens, o direito, como o lado do certo e da ordem. As mulheres seriam marcadas pela passionalidade, pelo transbordamento dos afetos (e, por isso, pela fraqueza), pela sensualidade, enquanto os homens seriam afeitos à racionalidade, à austeridade, à contenção devida e necessária das emoções, apregoada pelo senso comum. Às mulheres, seria concedido o torto, o incerto, o desviado; aos homens, o reto, o certo, a verdade. Às mulheres, a obscuridade e a confusão; aos homens, a clareza e o equilíbrio. Ao polo feminino, o podre, o excesso, o complexo, o dionísico; ao polo masculino, o saudável, o comedimento, o simples, o apolíneo. Aos homens, o mundo público, o poder, o externo, a voz; às mulheres, a vergonha, a reclusão, o ambiente doméstico, o 
interno, o silenciamento. À mulher "feiticeira"12 e enigmática, a perdição, o desejo e as pulsões sexuais; à mulher dominada, a submissão, a servidão e a passividade.

É especificamente nesse esquema de oposições homólogas que se insere a visão sobre o "galho esquerdo" que vimos há pouco. O lado materno será marcado, no longa, por grande parte dos traços femininos descritos acima. Dessa maneira, poderemos encontrar correspondências não só entre André e sua mãe, mas entre André e o feminino, de forma genérica. Voltemos, agora, a mais algumas cenas de LavourArcaica que podem nos ajudar na elucidação de tais características supostamente condenáveis do "galho esquerdo", oriundo do feminino.

Ainda em meio à grande sequência de cenas que marcam a chegada de Pedro ao quarto de pensão em que estava André, destaca-se uma lembrança do narrador-protagonista sobre o momento em que a mãe o acordava, quando era menino. Este flash da infância vem para ilustrar uma resposta de André a seu irmão Pedro: "A desunião da família começou bem antes do que você imagina, meu irmão". Nesse instante, temos conhecimento de como se dara a ligação entre André e sua mãe na infância, possibilitada "pelo vírus fatal dos afagos desmedidos", fato que, segundo André, teria sido o início da desunião da família, da ruína do clã, de sua discordância pessoal da lei paterna. Nessa cena, a matriarca vai até a cama de André menino e, de forma transbordante de afeto, acorda-o, deslizando suas mãos sobre o pequeno corpo do filho, enquanto canta versos em libanês. As mãos da mãe, neste instante, focalizadas em cut up (close em detalhe) para favorecer os efeitos pulsionais ${ }^{13}$ sobre o espectador, assim como em outras cenas do filme, conseguem simbolizar com exatidão o afeto transmitido ao filho, a "mácula" das paixões daqueles que pertencem ao lado esquerdo. Essas mãos, de certa forma sensuais - pois sugerem um deslizar quase sexual pelo corpo do filho, como se ali estivesse sendo passado a ele o desejo tão rechaçado pela fria ordem do pai -, são acompanhadas pelas doces palavras "Acorda, coração" e "Meu coração, meus olhos, meu cordeiro", dirigidas ao menino.

\footnotetext{
${ }^{12} \mathrm{~A}$ respeito desse imaginário de sensualidade, enigma, desejo e perdição secularmente associado à mulher, cf. Ferreira (2008), em seu artigo A "Outra Arte" das Soldadeiras.

${ }^{13}$ Vejam-se os efeitos pulsionais produzidos pelo close, o efeito de focalização, o efeito de vertigem, cf. AUMONT, 2002, p. 143.
} 
Neste exato instante, tem-se, no longa, a definitiva prova da ligação entre mãe e filho: suas imagens passariam a ser espelhadas, ao menos pelo olhar de André, desde a infância do protagonista.

E a "culpa" que André imprime à mãe na transmissão da passionalidade a ele não se esgota nessa sequência em que ela acorda o filho. Em meio a seu intenso monólogo na capela, após sentir a recusa da irmã Ana à prática do incesto, André vocifera: "Se o pai no seu gesto austero quis fazer da casa um templo, a mãe, transbordando no seu afeto, só conseguiu fazer dela uma casa de perdição". Mais uma vez, à matriarca e ao feminino é creditada a ruína familiar, dada pela sobreposição dos desejos. Também no momento em que conta a Pedro como pensou em se despedir de sua mãe antes de abandonar a casa, André menciona a filiação materna do desejo e das paixões:

\footnotetext{
Antes de sair, eu poderia ter dito à mãe: 'Nada mais aconteceu que eu ter sido aninhado na palha do teu útero por nove meses e ter recebido por muitos anos o toque doce da tua mão e da tua boca. É por isso que deixo a casa. É por isso que parto. (...) Eu e a senhora começamos a demolir esta casa.' (...) Mas tudo que eu pude ouvir, sem que ela dissesse nada, foram as trincas da louça antiga do seu ventre. Ouvi de seus olhos um dilacerado grito de mãe no parto.
}

Dessa maneira, André acaba por construir, para sua mãe, um ethos de passionalidade, de humanidade - daquela que não se resguarda do desejo -, e, consequentemente, a distancia do ethos de austeridade do pai. Ao mesmo tempo, coloca-se como herdeiro direto desses ethé vistos como negativos por Yohana (imagens, como vimos, oriundas do feminino na visão dóxica de mundo). Assim, o enunciador André acaba por filiar ambos, sua mãe e si mesmo, de alguma maneira, a uma imagem de subversão da ordem paterna: a mãe, por meio de seus "afagos desmedidos", mas ainda discreta e parcialmente submissa, em um ethos de moderação; já ele, pela via da radicalidade, de maneira mais corajosa e ruptora, pela fuga de casa e pelo embate travado frente a frente com a ordem paterna.

Todas essas imagens construídas por André frente a seu irmão (ou indiretamente aos olhos do telespectador), de alguma maneira, visariam suscitar possíveis representações patêmicas tais como um efeito de compaixão, por meio da adesão emocional - e também racional - de outrem ao discurso do narrador, este 
vítima de tamanha repressão e incompreensão, junto a sua mãe (e graças a ela), do duro "jugo" de ordem paterno. Dessa forma, seria possível que o interlocutor se sentisse “reprimido”, “interditado” como André, compreendendo seu sofrimento.

De acordo com Emília Mendes (apud MACHADO et all., 2007, p. 16), portanto, a "ficcionalidade permite um percurso de sentido capaz de demonstrar a construção da emoção." Suscitadas tais pathemes, a fraqueza de André ao ceder ao apelo das paixões (como no caso da relação incestuosa com Ana), assim como sua vontade de romper com a ordem paterna e assumir "seu lugar à mesa da família" seriam, em último caso, justificáveis e até plausíveis, frente ao ouvinte, dadas as condições próprias de sua criação materna e seus traços afetivo-comportamentais. Tal tentativa de mobilização das emoções do interlocutor é, a nosso ver, mais notória especificamente na fala seguinte de André, após sua consciência da impossibilidade de lutar contra a rígida ordem paterna. É como se a interdição imposta àqueles pertencentes ao lado esquerdo, neste momento, fosse patente, e André criasse para si um ethos de exclusão, de interdição: "Pertenço agora como nunca à família dos enjeitados, dos proibidos, dos sem-afeto ${ }^{14}$, dos sem-sossego, dos intranquilos."

Cabe-nos ressaltar, todavia, que a postura de André frente à ordem paterna não é tão simples e homogênea como parece. O “filho pródigo" nem sempre parece romper com a ordem paterna e filiar-se à lógica materna do feminino. Pelo contrário: até mesmo por seu caráter agônico e conflituoso, o protagonista, por vezes, assume o discurso do masculino. Isso é perceptível, por exemplo, nos próprios momentos em que André "culpa" a mãe - protótipo da mulher responsável pela desgraça familiar - por seu "desassossego" e pela desunião do clã, ou mesmo quando o protagonista parece querer tomar o lugar de poder do pai à mesa, na acirrada cena da discussão final entre os dois. Dessa maneira, é importante ponderar que, diante de um personagem tão dilacerado e ambíguo como André, é arriscado buscar-se tranquilidade e “certezas absolutas" em seu jogo de filiação ao feminino e/ou ao masculino.

\footnotetext{
${ }^{14}$ É interessante perceber como André, mesmo se assumindo na maior parte de seu discurso como aquele marcado pelo excesso de afeto materno, apresenta-se, paradoxalmente, como o sem-afeto neste momento de cólera frente a Ana. Tal traço não deixa de confirmar o conflito e a intranquilidade que permeiam a construção do personagem.
} 


\section{ENSAIANDO (IN)CONCLUSÕES: MÃE E FILHO, ENTRE A RUPTURA E A SUBMISSÃO}

Em LavourArcaica, a matriarca, apesar de ser vista pelo protagonista como uma figura de certa maneira subversiva, pela transmissão a André de seu transbordamento passional e sensual - contrário à austeridade da lei paterna -, aparece extremamente limitada em sua transgressão. Tendo consciência da necessidade de submeter-se, e as seus filhos, à ordem de Yohana, a mãe, apesar de não estar alheia aos acontecimentos e à repressão em que vivia, acaba por não conseguir romper efetivamente com a palavra paterna, o que é perceptível, inclusive, pelo silêncio extremo que domina suas aparições em quase todo o longa.

O filho André, no momento em que retorna à casa do pai e acaba por sujeitar-se novamente à sua ordem - o que é patente após a cena da discussão entre Yohana e o protagonista na mesa de jantar - acaba, dessa maneira, por filiarse definitivamente à condição feminina da mãe: acabará por seguir o mesmo destino de submissão e silenciamento que ela. Os ensinamentos paternos de que "o gado sempre volta ao cocho", de que "temos olhos voltados para frente e olhos voltados para trás" e de que "estamos sempre indo para a casa" tornam-se, então, realidade: André, assim como a mãe, também seria acometido, ao final, pelo eterno retorno e submissão à palavra da ordem, à lei paterna, ao apagamento de sua passionalidade.

\section{REFERÊNCIAS}

AMOSSY, Ruth (org). Imagens de si no discurso: a construção do ethos. São Paulo: Contexto, 2005.

AUMONT, Jacques. A Imagem. Campinas: Papirus, 2002.

BOURDIEU, Pierre. A dominação masculina. (trad. Maria H. Kühner). Rio de Janeiro: Bertrand Brasil, 1999. 
BUTCHER, Pedro. Cinema Brasileiro Hoje. São Paulo: Publifolha, 2005.

CHARAUDEAU, Patrick. Discurso Político. São Paulo: Contexto, 2006.

CHARAUDEAU, Patrick; MAINGUENEAU, Dominique. Dicionário de Análise do Discurso. $2^{\text {a }}$ ed., $1^{\mathrm{a}}$ reimpressão. São Paulo: Contexto, 2008.

FERREIRA, Ana Paula. A “Outra Arte" das Soldadeiras. Belo Horizonte: Faculdade de Letras da UFMG, 2008. Texto mimeografado.

LAVOURARCAICA. Dir. Luiz Fernando Carvalho. Drama. Brasil: Europa Filmes, 2001. 163 min., cor, DVD duplo de extras.

LIMA, Helcira Maria Rodrigues de. Na tessitura do Processo Penal: a argumentação no Tribunal do Júri. 2006. Tese (Doutorado em Estudos Lingüísticos). Belo Horizonte: Faculdade de Letras da UFMG.

MACHADO, Ida Lucia; MENEZES, William; MENDES, Emília (orgs.). As emoções no discurso. Rio de Janeiro: Lucerna, 2007. v. 1.

MELLO, Renato de. O silêncio faz sentido. In: MAGALHÃES, José Sueli de; TRAVAGLIA, Luiz Carlos (org.). Múltiplas perspectivas em Lingüística. Uberlândia: EDUFU, 2008. p. 2588-2594.

NASSAR, Raduan. Lavoura Arcaica. $3^{\text {a }}$ ed. rev. pelo autor. São Paulo: Companhia das Letras, 1989.

PERROT, Michelle. Minha história das mulheres. São Paulo: Contexto, 2007.

PLANTIN, Christian. A argumentação: história, teorias, perspectivas. São Paulo: Parábola Editorial, 2008.

SEDLMAYER, Sabrina. Ao lado esquerdo do pai. Belo Horizonte: Editora UFMG, 1997. - Lavoura Arcaica: um palimpsesto. São Paulo: Fundação Memorial da América Latina, 1999.

- Para além das imagens tempo: LavourArcaica. In: SEDLMAYER, Sabrina; $\overline{M A C I E L}$, Maria Esther (org.). Textos à flor da tela: relações entre literatura e cinema. Belo Horizonte: FALE/UFMG, 2004. 